\title{
Investigation of the Cutting Uid'S Ow and its \\ Thermomechanical Effect on the Cutting Zone Based on Uid-Structure Interaction (FSI) Simulation
}

Hui Liu ( $\sim$ h.liu@wzl.rwth-aachen.de)

RWTH Aachen University Laboratory for Machine Tools and Production Engineering:

Werkzeugmaschinenlabor der RWTH Aachen

Markus Meurer

RWTH Aachen University Laboratory for Machine Tools and Production Engineering:

Werkzeugmaschinenlabor der RWTH Aachen

\section{Daniel Schraknepper}

RWTH Aachen University Laboratory for Machine Tools and Production Engineering:

Werkzeugmaschinenlabor der RWTH Aachen

Thomas Bergs

RWTH Aachen University Laboratory for Machine Tools and Production Engineering:

Werkzeugmaschinenlabor der RWTH Aachen

\section{Research Article}

Keywords: Cutting Fluid Simulation, Fluid-Structure-Interaction, Orthogonal cutting, Heat transfe

Posted Date: November 29th, 2021

DOI: https://doi.org/10.21203/rs.3.rs-1104094/v1

License: (c) (1) This work is licensed under a Creative Commons Attribution 4.0 International License.

Read Full License 


\title{
Investigation of the cutting fluid's flow and its thermomechanical effect on the cutting zone based on fluid-structure interaction (FSI) simulation
}

\author{
Hui Liu ${ }^{1 *}$, Markus Meurer ${ }^{1}$, Daniel Schraknepper ${ }^{1}$ \\ and Thomas Bergs ${ }^{1,2}$ \\ ${ }^{1}$ Laboratory for Machine Tools and Production Engineering \\ (WZL) of RWTH Aachen University, Campus-Boulevard 30, \\ Aachen, 52074, Germany. \\ ${ }^{2}$ Fraunhofer Institute for Production Technology IPT, \\ Steinbachstr. 17, Aachen, 52074, Germany.
}

*Corresponding author(s). E-mail(s): h.liu@wzl.rwth-aachen.de;

\begin{abstract}
Cutting fluids are an important part of today's metal cutting processes, especially when machining aerospace alloys. They offer the possibility to extend tool life and improve cutting performance. However, the equipment and handling of cutting fluids also raises manufacturing costs. To reduce the negative impact of the high cost of cutting fluids, cooling systems and strategies are constantly being optimized. In most existing works, the influences of different cooling strategies on the relevant process parameters, such as tool wear, cutting forces, chip breakage, etc., are empirically investigated. Due to the limitations of experimental methods, analysis and modeling of the working mechanism has so far only been carried out at a relatively abstract level. For a better understanding of the mechanism of cutting fluids, a thermal coupled two-dimensional simulation approach for the orthogonal cutting process was developed in this work. This approach is based on the Coupled Eulerian Lagrangian (CEL) method and provides a detailed investigation of the cutting fluid's impact on chip formation and tool temperature. For model validation, cutting tests were conducted on a broaching machine. The simulation resolved the fluid behavior in the
\end{abstract}


cutting area and showed the distribution of convective cooling on the tool surface. This work demonstrates the potential of CEL based cutting fluid simulation, but also pointed out the shortcomings of this method.

Keywords: Cutting Fluid Simulation, Fluid-Structure-Interaction, Orthogonal cutting, Heat transfe

\section{Nomenclature}

\begin{tabular}{lll}
\hline Symbol & Unit & Meaning \\
\hline$A$ & $m^{2}$ & Surface area where the heat transfer takes place \\
$D_{\text {nozzle }}$ & $m m$ & Nozzle diameter \\
$h$ & $W /\left(m^{2} \cdot K\right)$ & heat transfer coefficient \\
$h_{e}$ & $m m$ & Uncut chip thickness \\
$\dot{Q}_{c o v}$ & $\mathrm{~J} / \mathrm{s}$ & Heat dissipation by convective cooling \\
$\dot{Q}_{s}$ & $\mathrm{~J} / \mathrm{s}$ & Heat generation at the contact surface between \\
$\dot{Q}_{\text {tool }}$ & & tool and workpiece \\
& $\mathrm{J} / \mathrm{s}$ & Heat flow from the tool-chip interface into the \\
$T$ & & cutting tool \\
$T_{0}$ & ${ }^{\circ} \mathrm{C}$ & Temperature \\
$T_{f l u i d}$ & ${ }^{\circ} \mathrm{C}$ & Room temperature \\
$T_{m}$ & ${ }^{\circ} \mathrm{C}$ & Temperature of cutting fluid \\
$T_{\text {tool }}$ & ${ }^{\circ} \mathrm{C}$ & Melting temperature \\
$T_{w a l l}$ & ${ }^{\circ}$ & Tool temperature on the workpiece tool contact \\
$T_{w p}$ & ${ }^{\circ} \mathrm{C}$ & surface \\
& ${ }^{\circ} \mathrm{C}$ & Tool surface temperature \\
$T_{f}$ & ${ }^{\circ} \mathrm{C}$ & Workpiece temperature on the workpiece tool \\
$\dot{V}_{C F}$ & $l / m i n$ & contact surface \\
$\varepsilon$ & - & Reference temperature of friction \\
$\dot{\varepsilon}$ & ${ }^{-} 1$ & Flow rate of the cutting fluid \\
$\dot{\varepsilon}$ & $s^{-} 1$ & Equivalent plastic strain \\
$\varepsilon_{f}$ & - & Plastic strain rate \\
$\mu$ & - & Reference plastic strain rate \\
$\mu_{0}$ & - & Fracture strain \\
$\sigma$ & $M P a$ & Friction coefficient \\
$\sigma_{e q}$ & $M P a$ & Friction coefficient at ambient condition \\
$\sigma_{m}$ & $M P a$ & Flow stress \\
\hline & & Equivalent stress \\
\hline & Mean stress \\
\hline
\end{tabular}




\section{Abbreviation}

\begin{tabular}{ll}
\hline Abb. & Description \\
\hline CAD & Computer Aided Design \\
CFD & Computational Fluid Dynamics \\
CEL & Coupled Eulerian-Lagrangian \\
FEM & Finite Element Method \\
FSI & Fluid-Structure Interaction \\
VOF & Volume Of Fluid \\
\hline
\end{tabular}

\section{Introduction}

Cutting fluids are widely used in the manufacturing process for cooling, lubricating the cutting area, reducing tool wear, removing chips to improve productivity and surface quality. Particularly in the machining of heat-resistant aerospace alloys, such as Inconel 718, the use of cutting fluids plays an important role in increasing tool life due to the extreme thermal and mechanical tool loading. Despite its advantages, wet cutting has been criticized for economic and ecological reasons since the early 1990s. Surveys in the German automotive industry revealed that the cost of manufacturing parts related to the cutting fluid was several times higher than the cost of tools [1]. The proper use of cutting fluids therefore has an essential impact on the economics of the manufacturing process.

In the last few decades, the effect of cutting fluids on different processes has been extensively researched. Sørby and Tønnessen [2] studied the effect of flank and rake surface cooling at different nozzle diameters and observed no significant advantage of combined flank and rake face cooling compared with only rake face cooling. In contrast, Diniz et al. [3] observed in turning tests that the longest tool life was achieved when the cutting fluid is either applied to both rake and flank face or only to the flank face with low flow rates. The results of these two specific cases showed that the conclusions drawn from one cutting condition are not directly transferable to other processes or materials. Therefore, cooling strategies must be specifically tailored to the cutting conditions to maximize their efficiency. To achieve this goal, it is essential to understand the mechanism of thermomechanical effects of cutting fluids.

As the experimental methods for cutting fluid investigation had reached their limits due to the restricted accessibility in the machining process, numerical simulations have been increasingly used. The pioneering work was started in 1996 by $\mathrm{Li}$ [4], who extended the finite element (FE) chip formation simulation to define a convective heat transfer model for chip and tool surfaces. The results showed that overhead jet cooling was more effective than flank face cooling with resprect to a lower tool temperature. Courbon et al. [5] further developed the model and analyzed not only the thermal loads, but also the 
mechanical effect of the cutting fluid. The results revealed that high-pressure rake face cooling had a significant effect on the chip contact length and the cutting force, but no effect on the chip curvature. Both Li's and Courbon's studies based on pure FE simulation. The flow behavior thereby was not described in full detail, so that their results can only be used for qualitative, but not for quantitative studies.
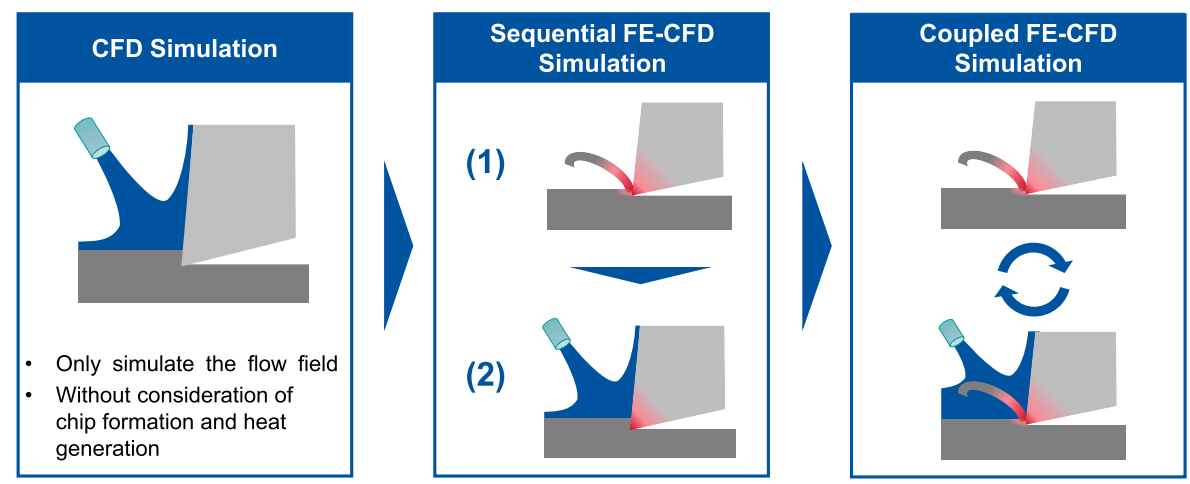

Fig. 1 Development of the flow simulation for the analysis of cutting fluid

With the later development of computational fluid dynamics (CFD), a more accurate simulation of the flow field could be achieved. The development of CFD-based cutting fluid simulation can be divided into three stages, as shown in Figure 1. In the first stage, pure CFD simulations were performed to investigate the relationship between the tool geometry and the local flow velocity, without considering chip formation and heat generation in the process. The efficiency of the cutting fluid can be improved by modifying the tool shape to promote local flow rate. Fallenstein and Aurich [6] presented a thermal coupled simulation approach to investigate heat flux between tool and cutting fluid in drilling. The authors assumed a constant tool temperature and evaluated the cooling efficiency of different cooling conditions. The results revealed that the cooling effect can be improved if the distance between the cooling nozzles is reduced. Beer et al. [7] improved the flank face design of a carbide twist drill based on CFD analysis and achieved a tool life improvement of about $50 \%$. Fang [8] used CFD to investigate the effect of adding cooling channels to the tool flank face. The simulation and experimental results showed that the tool life can be doubled with the flank surface cooling channel.

Although cutting fluid simulations are widely used in the analysis of machining processes, it is still a challenge to quantitatively model the thermomechanical effects of cutting fluids. This is not only due to the complexity of the fluid itself, but also to the changes in the geometric boundaries during machining. Both chip formation and tool movement change the solid boundaries of the flow field and thus affect the flow state. Therefore, to achieve better 
accuracy, FE cutting simulation was combined with CFD in the further development. Klocke et al. [9] presented a numerical model based on the Coupled Eulerian-Lagrangian (CEL) method. This method can calculate the mechanical effects of cutting fluids on chip formation and the thermal effects of tool temperature in one simulation environment. Helmig et al. [10] presented an interface program to combine the chip formation simulation with the CFD. The results indicated the formation of a flow stagnation zone in the cutting zone, which reduced the cooling effect. Oezkaya and Iovkov [11] linked the FE chip formation simulation of the twist drilling to the thermal coupled CFD via an interface program. The verified chip form and heat source were used as boundary conditions in the CFD model. The results showed that even small chips can cause a large reduction in flow rate in the cutting zone, which can shorten tool life and lead to poor chip evacuation. This approach significantly improved the accuracy of the simulation as it considers the realistic chip shape and heat source distribution.

Based on the results of Klocke et al. [9], CEL-based cutting fluid simulation were further developed in this work. The innovation of this paper is in two aspects: In the first part, a standard approach for combining cutting fluid simulation and chip formation simulation based on coupled Euler-Lagrange methods is developed and a validation process has been presented. Based on the simulation results, the formation of the stagnation zone of cutting fluid in the cutting area and the distribution of convection cooling on the tool rake face were investigated. In the following section, the working principle of CEL is presented first. Section 3 introduces the experimental setup for the validation test. The empirical data were used as a data base to validate the model parameters. The subsequent analysis of the experimental and simulation results reveals the thermomechanical effects of the cutting fluid. Finally, the advantages and disadvantages of the CEL method are summarized.

\section{Numerical model}

The simulation approach in this paper can be divided into three steps. In the first step, the material models were validated by means of the measured cutting forces. A calibrated material model played a decisive role in the subsequent thermal analysis, since in the simulation, $90 \%$ of the mechanical energy converted into heat [12], so that the definition of heat source related directly to the cutting forces. In the second step, the heat transfer coefficient between the workpiece and the tool was assumed to be constant and was verified with a single-point measurement of the tool temperature. Finally, the effects of the cutting fluid were simulated using a thermal coupled CEL model.

\subsection{Simulation of specific cutting forces}

The CEL model used for the cutting simulation is a feature of the commercial software ABAQUS (Version 6.14). Figure 2 shows the setup of the boundary conditions. The CEL model consisted of two simulation domains: Eulerian 
and Lagrangian Domain. The Eulerian domain defined the workpiece and the cutting fluid with the volume fraction. The Lagrangian domain discretized the cutting tool. The tool was considered as an ideal rigid body and therefore the simulation ignored tool wear and tool deformation.

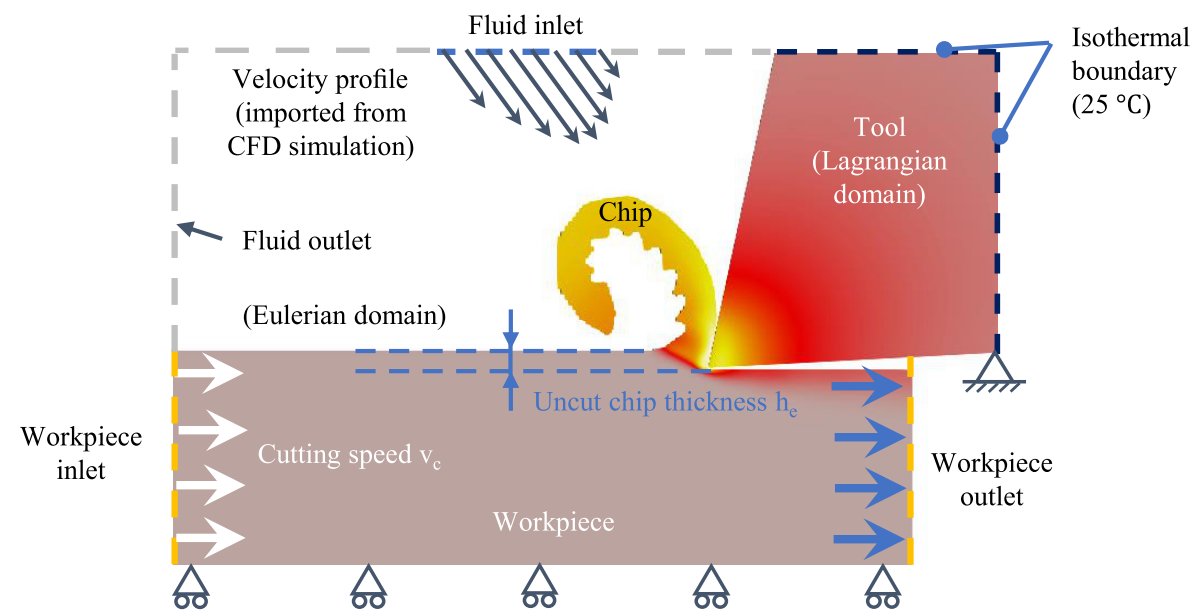

Fig. 2 Model setup of 2D-orthogonal cutting with the CEL-method

The model simulated the transient procedure. Each time step was divided into two sub-steps. First, a Lagrangian step calculated the motion of the chip and cutting fluid and the interaction between the different parts. Then, a remap step transformed the results from the Lagrangian mesh into the spatially fixed Eulerian mesh [13]. This method avoided mesh distortions and numerical instabilities at large deformations and was therefore suitable for cutting simulations. Since the remap process resulted in a loss of precision, the grid in the cutting area must be sufficiently fine to ensure the accuracy of the calculations. Based on the sensitivity test, the grid size of the cutting area was defined as $6 \mu \mathrm{m}$. The mesh consisted of structured hexahedral elements to avoid stress singularity and improve computational performance.

In the cutting process, workpieces are subjected to high temperatures and large strain rates. For modeling the plasticity of the workpiece, the JohnsonCook constitutive model was utilized. The Johnson-Cook model is one of the most commonly used material model for cutting simulations [14]. Its mathematical expression is shown in Eq. 1 [15].

$$
\sigma=\left(A+B \cdot \varepsilon^{n}\right) \cdot\left(1+C \cdot \ln \left(\frac{\dot{\varepsilon}}{\dot{\varepsilon_{0}}}\right)\right) \cdot\left(1-\left(\frac{T-T_{0}}{T_{m}-T_{0}}\right)^{m}\right)
$$

The materials investigated in this work were AISI 1045 and Inconel 718. AISI 1045 is a medium carbon steel commonly used for automotive parts and hand tools. Although this material can in principle be processed dry due to its good machinability, it was chosen because it has already been studied in many 
research projects and relevant material data and models are available [16]. The nickel-base alloy Inconel 718, in contrast, is a high-temperature material that is almost exclusively wet machined in practice. Therefore, the study of the working mechanism of cutting fluids in machining processes for industrial applications is of great importance.

The chips of Inconel 718 show a serrated shape, which is caused by adiabatic shear and damage-related crack initiation and propagation [17]. The simulation in this work used the Johnson Cook damage criterion to describe serrated chip formation. The mathematical expression was defined as follows [18].

$$
\begin{aligned}
\varepsilon_{f}= & \left(D_{1}+D_{2} \cdot \exp \left(D_{3} \cdot \frac{\sigma_{m}}{\sigma_{e q}}\right)\right) \cdot\left(1+D_{4} \cdot \ln \left(\frac{\dot{\varepsilon}}{\dot{\varepsilon_{0}}}\right)\right) . \\
& \left(1+D_{5} \cdot\left(\frac{T-T_{0}}{T_{m}-T_{0}}\right)^{m}\right)
\end{aligned}
$$

The friction was also defined in the cutting simulation, since it plays a decisive role for the deformation of the main shear zone, chip thickness, chip flow direction, cutting force and temperature [19]. The later simulation used the temperature-dependent friction model developed by Puls and Klocke et al. [20]. The coefficient of friction can be expressed as:

$$
\mu= \begin{cases}\mu_{0} & T<T_{0} \\ \mu_{0} \cdot\left(1-\left(\frac{T-T_{f}}{T_{m}-T_{f}}\right)^{m_{f}}\right) & T \geq T_{0}\end{cases}
$$

The parameters of the friction model for the contact pairing of AISI 1045 and Inconel 718 with carbides were determined by Puls [20] in and by Seimann in [21]. The initial temperature condition of the model was defined as $25^{\circ} \mathrm{C}$. Since the upper and right boundaries of the tool were far away from the heat source and the cutting time was short, they were considered as isothermal boundaries. Table 1 summarizes the parameters of the material and friction models used in this work.

\subsection{Determination of the thermal contact conductance}

Under dry machining conditions, the heat flow into the tool equals the sum of the heat generated at the tool surface and the shear zones, the heat transfer between tool and workpiece, the heat radiation as well as the air convection. The heat losses due to radiation and convection by air are much lower than the heat transfer between tool and workpiece, therefore only the contact heat transfer between solid parts was considered in the simulation [23]. The heat flow from the tool-chip interface into the cutting tool can be defined as

$$
\dot{Q}_{\text {tool }}=\dot{Q}_{s}+k \cdot A \cdot\left(T_{w p}-T_{\text {tool }}\right)
$$

where $\dot{Q}_{s}$ is the heat flow generated at the surface of the tool and $k$ the thermal contact conductance coefficient. The coefficient $k$ is a function of the material properties of the contact pair as well as the surface topology and the pressure between the contact surfaces [24]. In this work, $k$ is assumed to be 
Table 1 Parameters of the material and friction models

\begin{tabular}{|c|c|c|c|c|c|c|c|}
\hline \multicolumn{8}{|c|}{ Johnson Cook material constitutive model of Inconel 718 [22] } \\
\hline & & $C$ & $m$ & $n$ & $T_{m}$ & $T_{0}$ & $\dot{\varepsilon}_{0}$ \\
\hline$[\mathrm{MPa}]$ & {$[\mathrm{MPa}]$} & - & - & - & {$\left[{ }^{\circ} \mathrm{C}\right]$} & {$\left[{ }^{\circ} \mathrm{C}\right]$} & $\mathrm{s}^{-1}$ \\
\hline 1200 & 1284 & 0.006 & 1.2 & 0.54 & 1800 & 25 & $10^{-3}$ \\
\hline
\end{tabular}

Johnson Cook damage model of Inconel 718 [22]

\begin{tabular}{ccccc}
\hline$D_{1}$ & $D_{2}$ & $D_{3}$ & $D_{4}$ & $D_{5}$ \\
\hline 0.04 & 1.2 & -1.45 & 0.04 & 0.89 \\
\hline
\end{tabular}

Johnson Cook material constitutive model of AISI 1045 [16]

\begin{tabular}{cccccccc}
\hline $\begin{array}{c}A \\
{[\mathrm{MPa}]}\end{array}$ & $\begin{array}{c}B \\
{[\mathrm{MPa}]}\end{array}$ & $\begin{array}{c}C \\
-\end{array}$ & $\begin{array}{c}m \\
-\end{array}$ & $\begin{array}{c}T_{m} \\
{\left[{ }^{\circ} \mathrm{C}\right]}\end{array}$ & $\begin{array}{c}T_{0} \\
{\left[{ }^{\circ} \mathrm{C}\right]}\end{array}$ & $\begin{array}{c}\dot{\varepsilon}_{0} \\
\mathrm{~s}^{-1}\end{array}$ \\
\hline 553.1 & 600.8 & 0.0134 & 1 & 0.234 & 1460 & 20 & 1 \\
\hline
\end{tabular}

\begin{tabular}{|c|c|c|c|c|c|}
\hline \multicolumn{3}{|c|}{ Friction model of Inconel 718 [21] } & \multicolumn{3}{|c|}{ Friction model of AISI 1045 [21] } \\
\hline $\begin{array}{c}\mu_{0} \\
-\end{array}$ & $\begin{array}{c}m_{f} \\
-\end{array}$ & $\begin{array}{c}T_{f} \\
{\left[{ }^{\circ} \mathrm{C}\right]}\end{array}$ & $\begin{array}{c}\mu_{0} \\
-\end{array}$ & $\begin{array}{c}m_{f} \\
-\end{array}$ & $\begin{array}{c}T_{f} \\
{\left[{ }^{\circ} \mathrm{C}\right]}\end{array}$ \\
\hline 553.1 & 600.8 & 0.0134 & 1 & 0.234 & 1460 \\
\hline
\end{tabular}

constant. Its value depends on cutting conditions and was determined using the inverse method. First, the simulation calculated the tool temperature with an assumed $k$-value. The $k$-value was then adjusted by comparing the simulated tool temperature with the experimental data until satisfactory agreement was achieved.

\subsection{Simulation of flow field and convective heat transfer}

The Newton's law defined the convective cooling as follows:

$$
\dot{Q}_{\text {cov }}=h \cdot A \cdot\left(T_{\text {wall }}-T_{\text {fluid }}\right)
$$

The value of the heat transfer coefficient $h$ depends on the flow behavior of the cutting fluid. The CEL method determines the flow behavior with the continuity, momentum, and energy equations. The cutting fluid was assumed to be an incompressible Newtonian fluid. Turbulence, liquid evaporation, and air-liquid interactions were neglected.

The initial fluid velocity in the cutting simulation corresponds to the velocity distribution of the cutting fluid jet before it reaches the cutting zone. The jet is slowed down by air resistance before it reaches the cutting zone. The velocity distribution of the cutting fluid jet could not be measured experimentally. In order to determine the velocity of the cutting fluid jet as accurately 
as possible, the development of the jet velocity was simulated in ANSYS Fluent using the VOF model. The inlet condition was set to $\dot{V}_{C F}=1.6 \mathrm{l} / \mathrm{min}$, which matched the experimentally measured flow rate. The nozzle diameter of $D_{\text {nozzle }}=1.6 \mathrm{~mm}$ corresponds to the tested tool holder. The simulation describes the turbulent flow with the standard $\kappa-\epsilon$ model. Model parameters were Fluent default values. Figure 3 shows the fully developed pipe flow at the nozzle outlet and the velocity distribution of the cutting fluid jet.

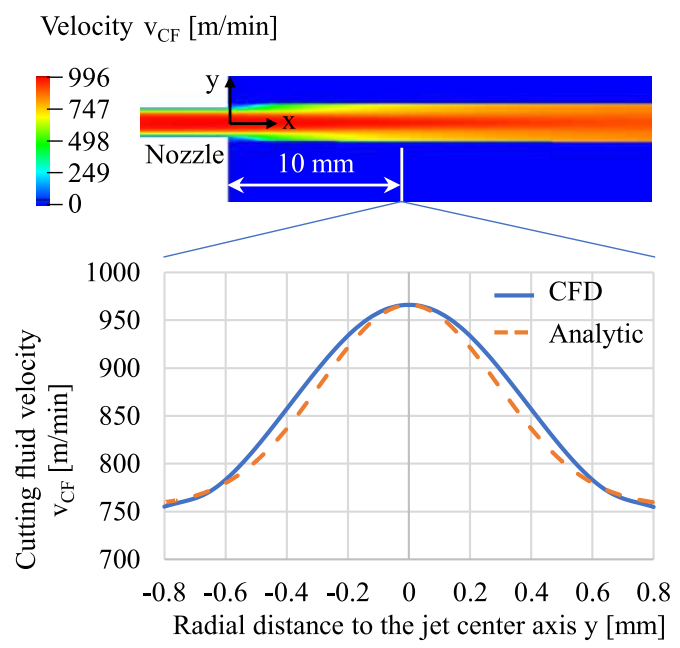

Fig. 3 Velocity profile of the free jet from multi-phase simulation

The CEL model imported the velocity distribution at a distance of $10 \mathrm{~mm}$ from the nozzle outlet as the initial cutting fluid velocity. ABAQUS could define the velocity distribution using the analytical approach. The mathematical expression of the setting was:

$$
v_{C F}=211.2 \cdot e^{-5.95 \cdot y^{2}}+755
$$

The dotted curve in Figure 3 is the analytical velocity distribution in ABAQUS, which is generally consistent with the CFD results.

All simulations were performed on a workstation with 16 processors. The workstation had a Xeon E5-2698 CPU with $2.2 \mathrm{GHz}$ clock frequency and computer memory of $32 \mathrm{~GB}$. The average simulation time of a millisecond process is about 30 hours for Inconel 718 and about 20 hours for AISI 1045.

\section{Experimental procedure}

The following subsections explain the experimental setup, the properties of the tools and workpieces. The sensors used and the parameter combination are also outlined. 


\subsection{Workpiece materials and cutting fluid}

To create a database for the model validation, orthogonal cutting tests were performed with Inconel 718 and AISI 1045. The Inconel 718 specimens had a shape of $2.7 \times 40 \times 120 \mathrm{~mm}^{3}$ and AISI 1045 specimens were $2.7 \times 33 \times 130 \mathrm{~mm}^{3}$. The microstructure showed that the two materials had a homogeneous grain distribution, see Figure 4.
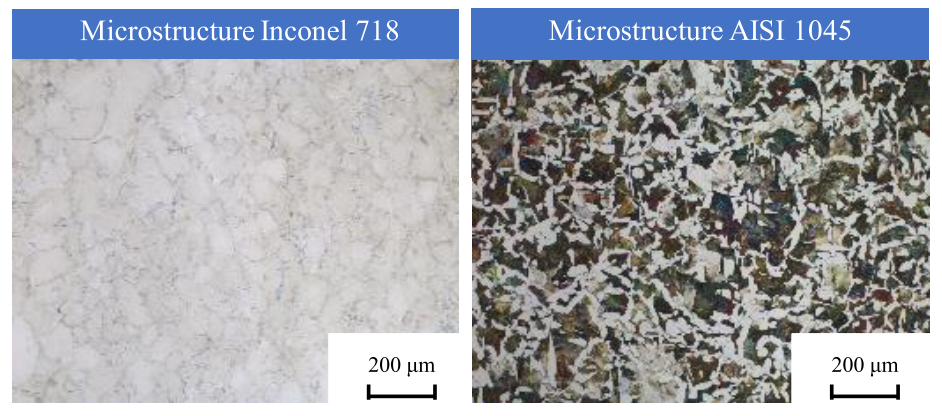

Fig. 4 Velocity profile of the free jet from multi-phase simulation

Table 2 shows a comparison of the physical properties of the Inconel 718 and the AISI 1045. The hardness was measured at various points on the workpiece and the other values came from the supplier's specification.

Table 2 Material properties of workpiece samples (at $20{ }^{\circ} \mathrm{C}$ )

\begin{tabular}{lcc}
\hline Workpiece materials & Inconel 718 & AISI 1045 \\
\hline Hardness & $425 \pm 3$ HV30 & $170 \pm 1$ HV30 \\
Thermal conductivity $k[\mathrm{~W} / \mathrm{mK}]$ & 10.3 & 48 \\
Heat capacity $C[\mathrm{~J} /(\mathrm{kg} \cdot \mathrm{K})]$ & 440.5 & 470 \\
Density $\rho\left[\mathrm{kg} / \mathrm{m}^{3}\right]$ & 8220 & 7820 \\
Young modulus $E[\mathrm{GPa}]$ & 217 & 214 \\
\hline
\end{tabular}

Compared to AISI 1045, Inconel 718 has lower thermal conductivity, which leads to heat build-up in the cutting zone and thus to higher cutting temperatures and thermally induced tool wear. Furthermore Inconel 718 retains its hardness even at high temperatures, resulting in higher mechanical tool loads. The cutting fluid used in the investigation was Variocut B 9 from Castrol. It was an oily, water insoluble liquid with a kinematic viscosity of $\nu_{C F}=11 \mathrm{~mm}^{2} \cdot \mathrm{s}^{-1}$ and a density of $\rho_{C F}=870 \mathrm{~kg} \cdot \mathrm{m}^{-3}$ respectively. Since the manufacturer did not provide the thermal properties, the later simulation used the textbook-defined parameters. The heat capacity of the cutting fluid was $C_{C F}=1950 \mathrm{~J} \cdot \mathrm{kg}^{-1} \cdot \mathrm{k}^{-1}$ and the thermal conductivity was $k_{C F}=0.13 \mathrm{~W} \cdot \mathrm{m}^{-1} \cdot \mathrm{k}^{-1}$ [25]. The sound speed in the fluid used for the Mie-Grüneisen equation amounted $c_{S}=1450 \mathrm{~m} \cdot \mathrm{s}^{-1}$. 


\subsection{Cutting Tools}

The cutting tools used in the tests were tailor-made by Sandvik Coromant from H13A carbide. Unlike mass-produced tools, this grooving tool has no coating and no chip-breaker. The tool has a rake angle of $\gamma=12^{\circ}$ and a clearance angle of $\alpha=3^{\circ}$. All cutting-edge roundings were measured with the Micro CAD optical measuring system from LMI Technologies and lay in the range of $R=5 \pm 0.2 \mu m$. During the cutting test, the tool temperature was measured by means of transmitting the infrared radiation through a glass fiber to a ratio pyrometer. To fix the glass fiber, all tools were drilled with electric discharge machining. Figure 5 shows the dimension and position of the measuring hole.

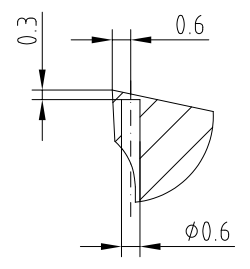

W $3: 1$

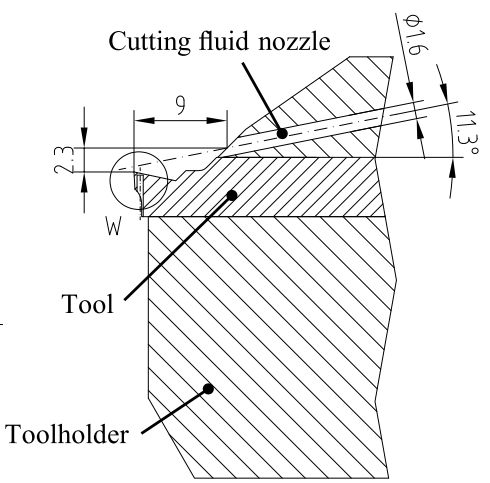

Fig. 5 Position of the measuring hole and the cutting fluid nozzle

The tool holder used was QS-LF123H20C-2525E from Sandvik Coromant. It had an inner channel for both rake face and flank face cooling. As this work investigated only the rake face cooling, the flank face channel was welded. The cutting fluid nozzle had a diameter of $D_{\text {nozzle }}=1.6 \mathrm{~mm}$. The nozzle exit was about $L=10 \mathrm{~mm}$ distant from the tool tip. The horizontal inclination of the nozzle measured $\theta=11.3^{\circ}$, as shown in Figure 5 .

\subsection{Experimental Set-Up and Procedure}

The cutting tests were conducted on a vertical broaching machine type RASX 8x2200x600M from the company Forst Technologie GmbH. Figure 6 shows the experimental setup. During the tests, the workpiece specimen was clamped on the broaching slide and moved at a constant speed from top to bottom against the cutting tool. The tool holder was mounted on the worktable and was attached to the Kistler dynamometer model Z21289. The dynamometer measured the cutting force $F_{c}$ and the thrust force $F_{t}$ during the test. To obtain the steady state cutting force, the average value of the measurement after 0.04 seconds was used. Figure 7 shows the measured signal and the evaluation range of the cutting force components. 


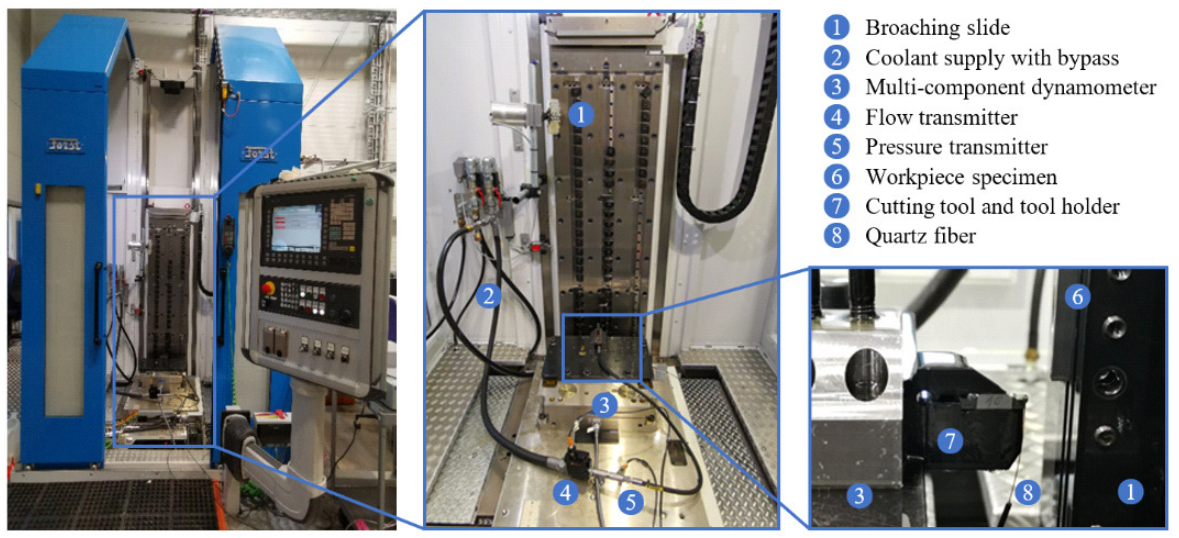

Fig. 6 Experimental setup of the orthogonal cutting experiment on a broaching machine with cutting fluid supply

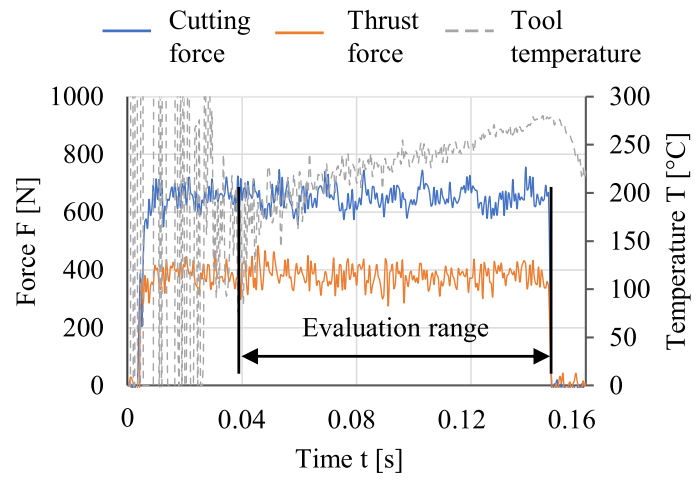

Fig. 7 Cutting force components and tool temperature

During the machining process the tool temperature was measured with the two-color ratio pyrometer model FIRE-1 from en2Aix. The advantages of twocolor ratio pyrometers lie in the high time resolution (up to $500 \mathrm{kHz}$ sampling rate) and independence from the emissivity of the measuring surface. Working principle of the two-color pyrometer can be found in [26]. The measuring range of the pyrometer used in this work is $200-1200{ }^{\circ} \mathrm{C}$. Outside the measurement range, the signal displayed only random noise. At the end of the cutting time, the tool temperature did not yet reach the steady state. Therefore, the transient tool temperature was simulated and compared with the measured temperature at the end of the cutting time. Table 3 summarizes the investigated process parameters. The cutting time is derived from the cutting speed and the workpiece length. Each test was performed three times with a new cutter to minimize the influence of tool wear and ensure statistical significance.

Each parameter combination was investigated under 5 bar cutting fluid conditions and dry respectively. The pressure is commonly used in practice 
for flood cooling. The machine tool supplied the cutting fluid with a built-in centrifugal pump and regulated the pressure with a bypass valve attached to the supply hose. An IFM SBU 625 flow sensor and an IFM PT5502 pressure sensor were installed to monitor the flow condition. Since it was not possible to collect the chip when cutting fluid was supplied, no chip shape analysis was performed.

Table 3 Investigated cutting parameters

\begin{tabular}{cccc}
\hline $\begin{array}{c}\text { Workpiece } \\
\text { materials }\end{array}$ & $\begin{array}{c}\text { Cutting speed } \\
v_{c}[\mathrm{~m} / \mathrm{min}]\end{array}$ & $\begin{array}{c}\text { Uncut chip thickness } \\
h_{e}[\mu \mathrm{m}]\end{array}$ & $\begin{array}{c}\text { Cutting time } \\
t[\mathrm{~s}]\end{array}$ \\
\hline Inconel 718 & 50 & 75 & 0.144 \\
Inconel 718 & 50 & 125 & 0.144 \\
Inconel 718 & 50 & 175 & 0.144 \\
Inconel 718 & 70 & 75 & 0.103 \\
Inconel 718 & 70 & 125 & 0.103 \\
Inconel 718 & 70 & 175 & 0.103 \\
AISI 1045 & 150 & 100 & 0.052 \\
AISI 1045 & 150 & 200 & 0.052 \\
AISI 1045 & 150 & 300 & 0.052 \\
AISI 1045 & 120 & 100 & 0.065 \\
AISI 1045 & 120 & 200 & 0.065 \\
AISI 1045 & 120 & 300 & 0.065 \\
\hline
\end{tabular}

\section{Results and discussion}

The following sections present the simulation and experimental results for Inconel 718 and AISI 1045, respectively. First, a comparison of the cutting force results shows the accuracy of the calibrated cutting model. Then, the mechanism of the cutting fluid is revealed by analyzing the streamline distribution and convective heat transfer results.

\subsection{Results of Inconel 718}

Figure 8 shows a comparison of the experimental and simulated cutting forces during the cutting of Inconel 718. For $h_{e}=75$ and $125 \mu \mathrm{m}$, the difference in cutting forces between dry and wet machining was very small. The simulated cutting forces are slightly higher than the measurements. This is due to the overestimation of the cooling effect in the simulation, which is explained in the later thermal analysis. At $h_{e}=175 \mu \mathrm{m}$ and $v_{c}=50 \mathrm{~m} / \mathrm{min}$, significant cutting force fluctuations were observed. The reason for this was tool wear due to the high thermal-mechanical load, even though new tools were used for each cut. When the cutting speed was increased, both the experimental and simulated cutting forces decreased slightly. This is due to the fact that the cutting process generates more heat and the stiffness of the workpiece decreases due to the thermal softening. 


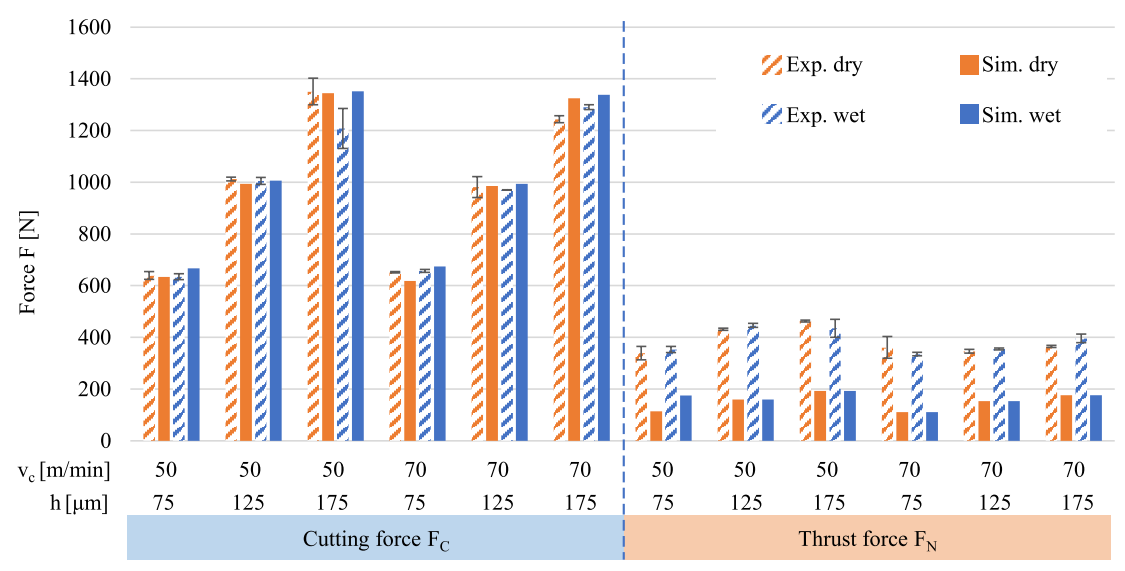

Fig. 8 Cutting force components of Inconel 718 cutting from experiments and simulations under dry and wet conditions

The measured thrust force increased slightly with increasing uncut chip thickness at a cutting speed of $v_{c}=50 \mathrm{~m} / \mathrm{min}$. At $v_{c}=70 \mathrm{~m} / \mathrm{min}$, the thrust force barely varied with the uncut chip thickness. The influence of the cutting fluid on the thrust force was not evident under the investigated cutting conditions. The simulated thrust deviated strongly from the experiments. One possible reason is that the thrust force is strongly influenced by tool wear. A small amount of wear occurred in the process but was not accounted for in the simulation [27]. Since the direction of thrust is perpendicular to the direction of cut, it did not contribute to the process heat and thus had no effect on the following thermal analysis.

Figure 9 shows the result of the simulated flow field. The streamline indicates the direction of the cutting fluid flow and the color indicates the velocity. The dark blue and purple colors shows the area where the fluid velocity was closed to zero. This area is called the stagnation zone. The stagnation zone appeared not only in the cutting area, but extended up to about $3 \mathrm{~mm}$ along the tool rake face. The size of the stationary zone was similar under different cutting conditions. In general, the stagnation zone deflects the cutting fluid jet and hinders the penetration of the fluid into the cutting area. It worked like a barrier and reduced the mechanical effect of the cutting fluid on the chip formation. Above the stagnation zone, the fluid accelerates along the rake face and the workpiece surface to several meters per second, eventually reaching about $v_{C F}=15 \mathrm{~m} / \mathrm{s}$. Since the high-speed flow was outside the cutting area, it does not contribute to convection cooling.

In the stationary zone, the flow formed various small vortices. The size of the vortices varied with the shape of the chip and the cutting speed. At lower uncut chip thickness, the bottom of the chip was completely in the stagnation zone, and no vortex formed at the front of the chip. As the uncut chip thickness 

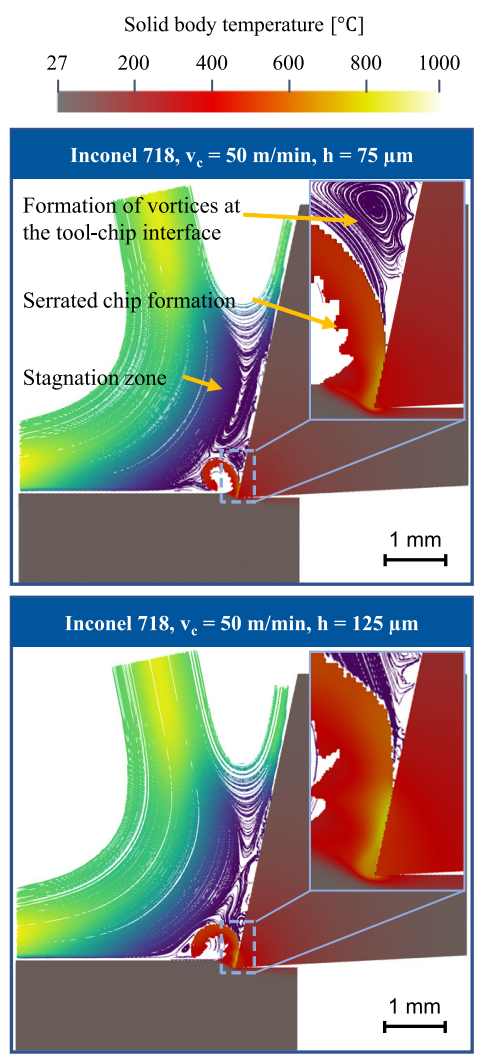

Inconel $718, \mathrm{v}_{\mathrm{c}}=\mathbf{5 0} \mathrm{m} / \mathrm{min}, \mathrm{h}=\mathbf{1 7 5} \mu \mathrm{m}$

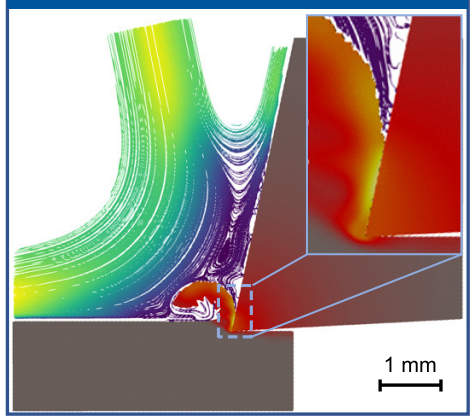

Flow velocity $[\mathrm{m} / \mathrm{s}]$

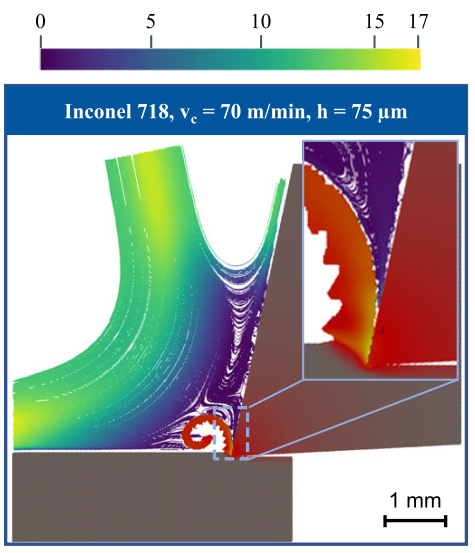

Inconel $718, \mathrm{v}_{\mathrm{c}}=70 \mathrm{~m} / \mathrm{min}, \mathrm{h}=125 \mu \mathrm{m}$

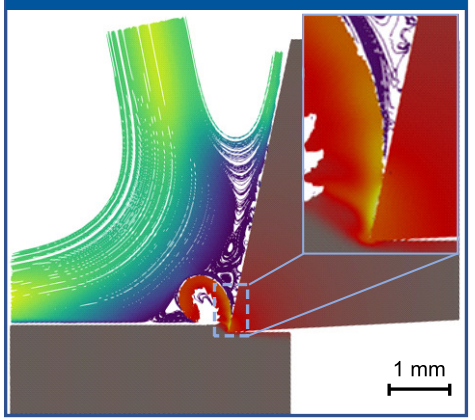

Inconel $718, \mathrm{v}_{\mathrm{c}}=\mathbf{7 0} \mathrm{m} / \mathrm{min}, \mathrm{h}=175 \mu \mathrm{m}$

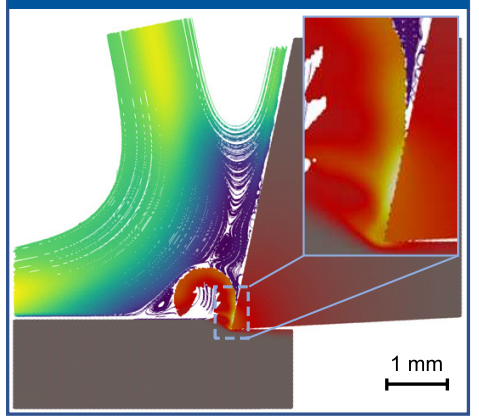

Fig. 9 Streamline of flow velocity vector and temperature distribution of workpiece and tool from 2D CEL simulations of Inconel 718

increased, the radius of the chip became larger and more vortices occurred due to the large variations in the local fluid velocity at the front of the chip.

A comparison of the measured and simulated tool temperatures can be seen in Figure 10. The measurement point is located $0.3 \mathrm{~mm}$ below the rake face as outlined in Section 3.1. With increasing uncut chip thickness, the cutting forces and heat generation became higher, and the tool temperature increased. 


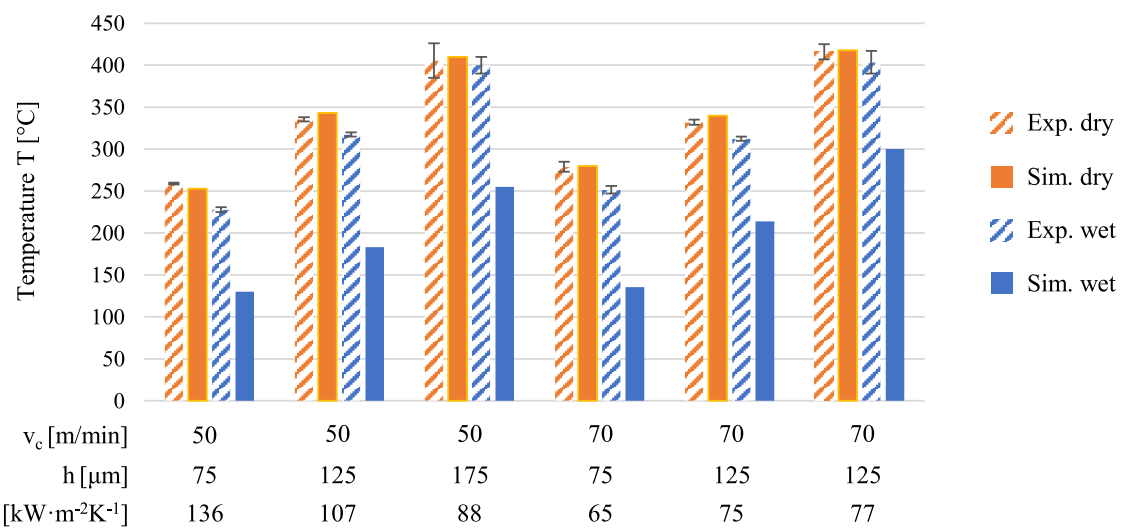

Fig. 10 Tool temperature for Inconel 718 cutting from experiments and simulations under wet and dry conditions at the measuring point ( $0.3 \mathrm{~mm}$ to the rake face)

Comparing the tool temperature at different cutting speeds reveals that a higher cutting speed caused an increase in tool temperature.

Under the influence of the cutting fluid, the measured tool temperature generally decreased. The lower the uncut chip thickness was, the higher the cooling effect of the cutting fluid was. This is because at lower uncut chip thickness, the curvature of the chip increased and the contact area between the tool and the chip became less, allowing the cutting fluid to enter the zone closer to the tool tip. At different cutting speeds, there was no significant difference in the cooling effect. The chip movement speed has apparently no effect on the cooling efficiency under the investigated conditions.

The simulated tool temperature in dry condition fits well with the experiment, but in wet condition was severely underestimated. Figure 11 shows the heat flux from the tool into the cutting fluid along the rake face. The heat flux first increased steeply to a peak value and then gradually dropped off. This is because the temperature difference between the tool and the cutting fluid was greatest near the cutting area and more heat was removed by the cutting fluid. The position of the highest heat flux varies with the uncut chip thickness and the cutting speed. As the uncut chip thickness increases, the distance between the highest heat flux and the tool tip becomes larger.

Based on the heat flux, the convective heat transfer coefficient can be derived with the equation:

$$
h_{\text {cov }}=\frac{\dot{q}_{\text {cool }}}{T_{\text {tool }}-T_{C F}}
$$

The heat transfer coefficient results in Figure 11 show a similar course to the heat flux. As the uncut chip thickness increased, the position of the maximum heat transfer coefficient moved away from the tool tip and became smaller in magnitude. The curves in the descending region, unlike the heat flux, nearly coincide for different uncut chip thicknesses. It is evident that the convective heat transfer coefficient is not only influenced by the fluid-solid temperature 


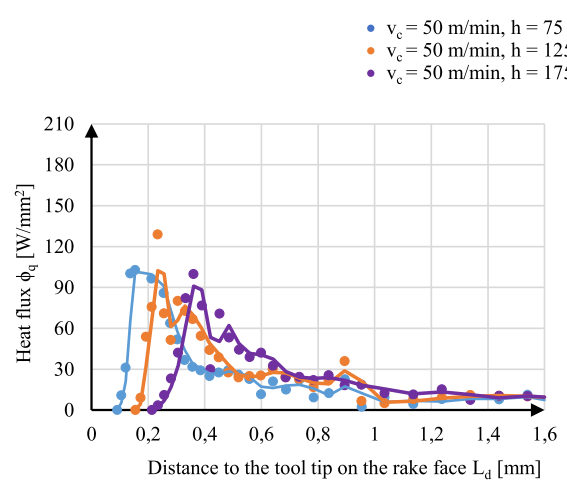

- $\mathrm{v}_{\mathrm{c}}=70 \mathrm{~m} / \mathrm{min}, \mathrm{h}=75 \mu \mathrm{m}$, tool chip contact length $=190 \mu \mathrm{m}$ - $\mathrm{v}_{\mathrm{c}}=70 \mathrm{~m} / \mathrm{min}, \mathrm{h}=125 \mu \mathrm{m}$, tool chip contact length $=300 \mu \mathrm{m}$

- $\mathrm{v}_{\mathrm{c}}=70 \mathrm{~m} / \mathrm{min}, \mathrm{h}=175 \mu \mathrm{m}$, tool chip contact length $=450 \mu \mathrm{m}$
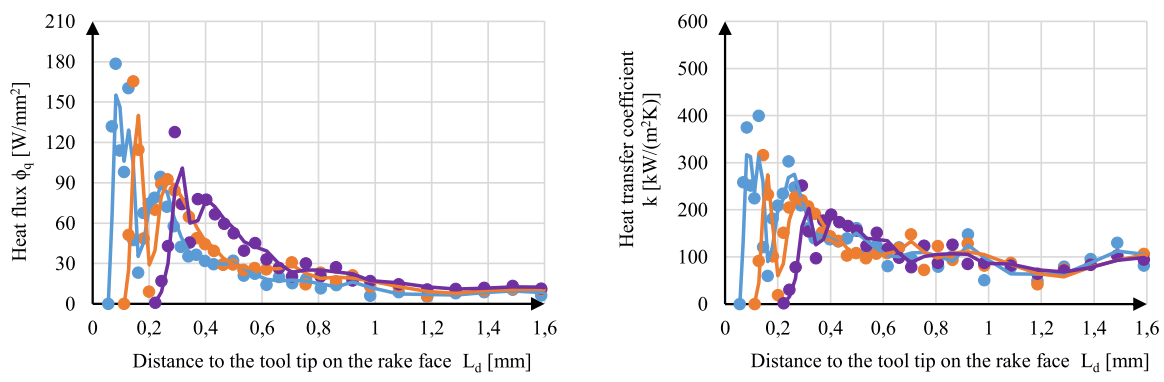

Fig. 11 Heat flux from the tool to the cutting fluid and derived heat transfer coefficient along the tool rake face for the investigated cutting parameters of Inconel 718

difference, but also related to the cutting conditions. For different cutting parameters, the cooling efficiency of the same cooling supply strategy was different.

The simulation results show the distribution of convective heat transfer. However, it cannot be determined quantitatively. The CEL method cannot accurately calculate the boundary layer flow. Figure 12 shows a comparison of the near-wall flow of the CEL model with the typical turbulent and laminar boundary flow simulated by CFD. The right side of the figure shows the flow velocity vector distribution in the cutting area. It revealed that the boundary layer on the Eulerian solid surface was completely neglected. The near-wall velocity was equal to the free stream velocity. On Lagrangian solid surfaces, the normal behavior was defined as hard contact and tangential behavior as frictionless. There was no kinetic energy loss in the boundary layer. The flow velocity had an irregular distribution. The magnitude was significantly higher than that of the free stream, which caused the overestimation of the cooling effect. 


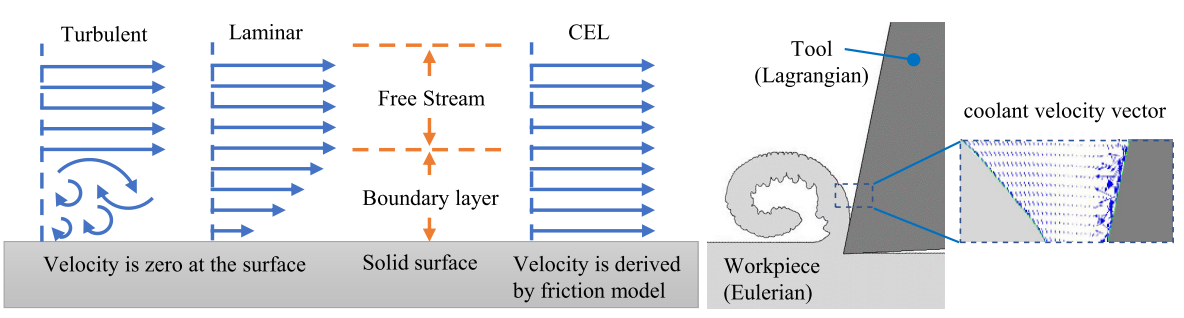

Fig. 12 Analysis of the boundary layer definition of the CEL model based on the simulation result

\subsection{Results of AISI 1045}

In this section, only three cutting parameters are analyzed. The other parameters were not measurable due to the low tool temperature and are therefore not considered. Figure 13 shows the streamline of the cutting fluid and the temperature of the solid part from the AISI 1045 simulation.

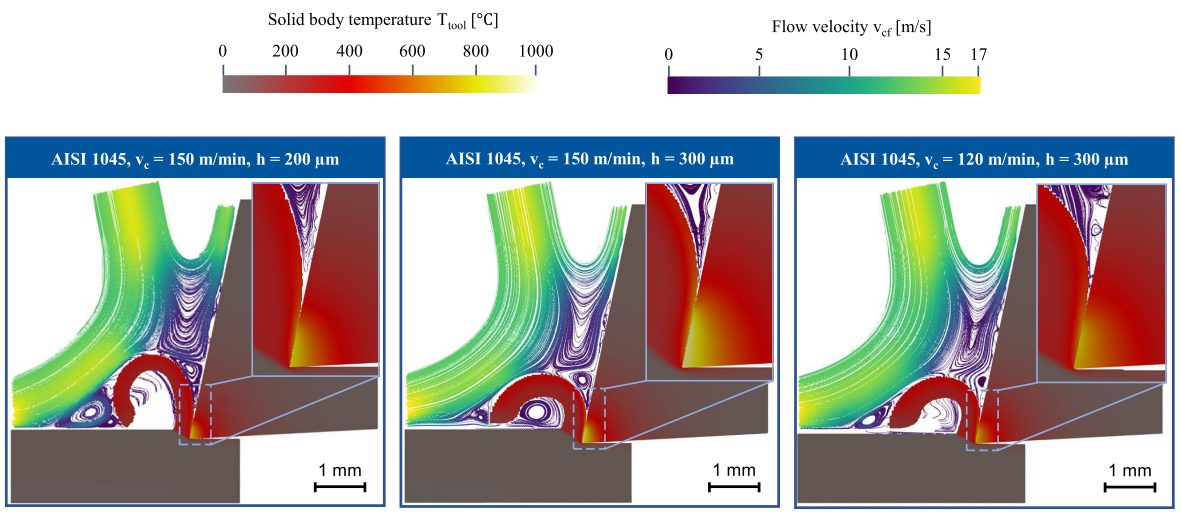

Fig. 13 Streamline of flow velocity vector and temperature distribution of workpiece and tool from 2D CEL simulations of AISI 1045

Although the chip shape of AISI 1045 was significantly different from that of Inconel 718, the area of the stagnation zone was similar. As the chip approached the brim of the stagnation zone, the high-speed fluid acted on the chip backside and pressed the chip flat.

Figure 14 shows the comparison of measured and simulated cutting force components. The measuring data revealed that at $v_{c}=150 \mathrm{~m} / \mathrm{min}$ and $h=300 \mu \mathrm{m}$, the cutting force decreased slightly under cutting fluid. For the other cutting conditions, the cutting fluid had barely any influence on the cutting force. The thrust force was significantly underestimated, comparable in the simulation of Inconel 718.

The measured and simulated tool temperatures are presented in Figure 15. The simulated results for dry cutting were consistent with the measured values, but the temperature with cutting fluid was underestimated. The main reason was the inaccurate solution of the boundary layer, which was discussed in 


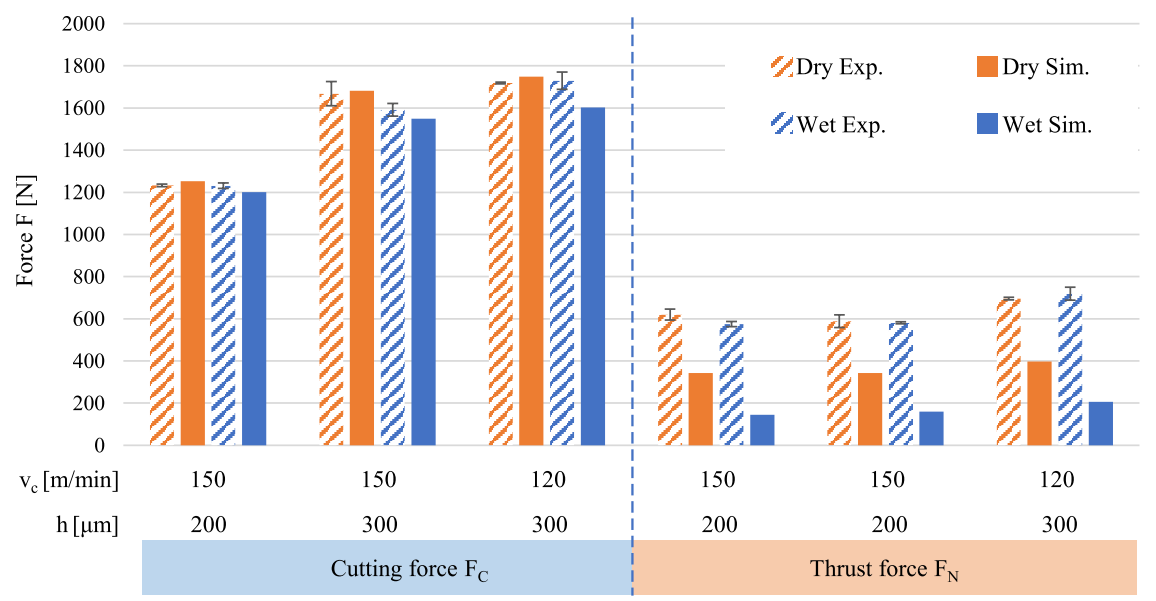

Fig. 14 Process forces of AISI 1045 cutting from experiments and simulations under dry and wet conditions

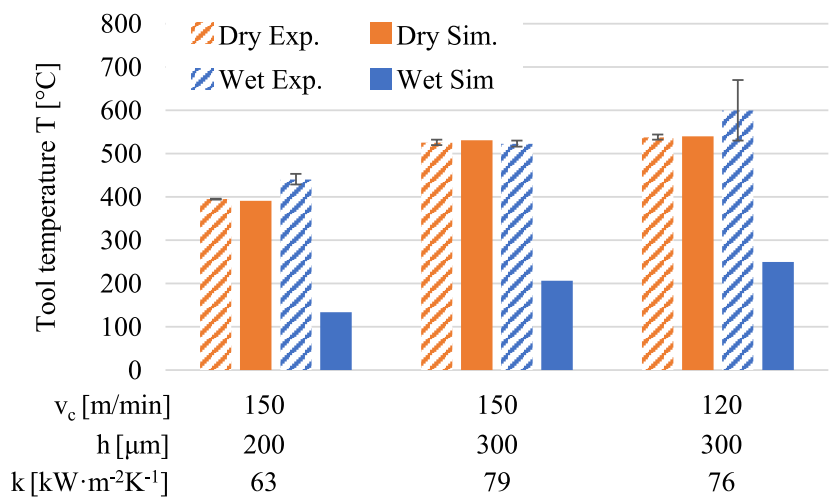

Fig. 15 Tool temperature for AISI 1045 cutting from experiments and simulations under wet and dry conditions at the measuring point ( $0.3 \mathrm{~mm}$ to the rake face)

Section 4.1. Figure 16 indicates the heat flux from the tool to the cutting fluid and the heat transfer coefficient on the tool rake face. In general, no heat flux occurred below a tool tip distance of $0.2 \mathrm{~mm}$. Afterwards a fast increase with following peak is visible, which finally falls off again. This is because near the cutting area, the tool temperature was higher and the temperature difference with the fluid was large, so the heat flux increased steeply. Before reaching maximum heat flux, the cooling effect was poor due to the small volume of cutting fluid and slow flow rate in the tool-chip interface. After the maximum, the heat flux gradually decreased because the temperature difference became smaller.

The effect of cutting conditions on the cooling efficiency can be observed by comparing the heat fluxes under different cutting conditions. The cutting 


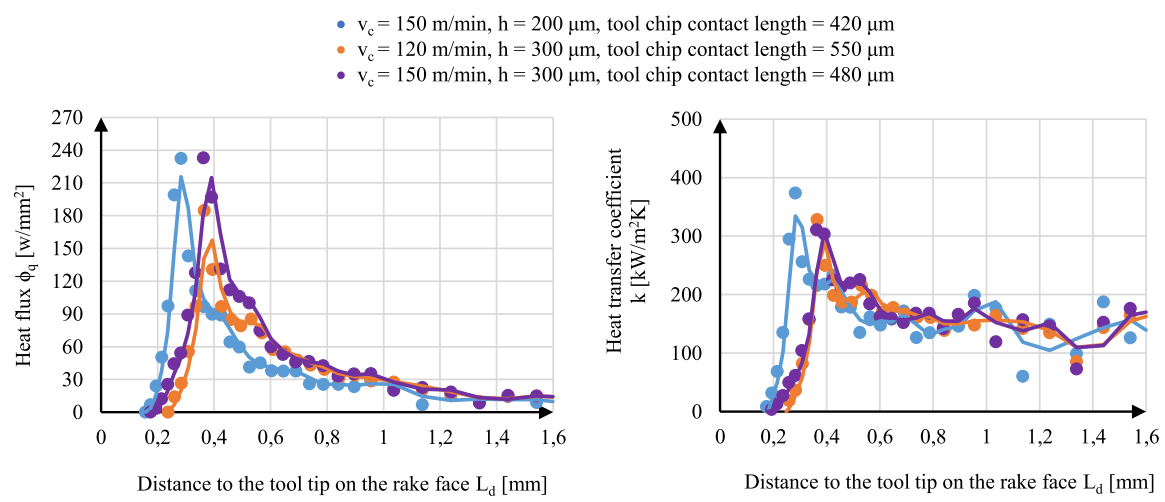

Fig. 16 Heat flux from the tool to the coolant and derived heat transfer coefficient along the tool rake face for the investigated cutting parameters of AISI 1045

parameters mainly influenced the position and magnitude of the maximum heat flux. As the uncut chip thickness increased, the contact length between the tool and the chip became longer, and the peak of the curve shifted away from the tool tip. At different cutting speeds, the location of maximum heat flux was the same but differed with magnitude. The heat transfer coefficient showed a similar course as the heat flux and reached the peak at the same position. In contrast to the heat flux, the heat transfer coefficient decreased slowly after the maximum. It settled then at a relative stable value. The reason for this is that the flow velocity of the cutting fluid in the stagnation zone was small and uniform, so that the heat transfer coefficient remained at a nearly constant value. The general trend of the heat transfer coefficient shows that the maximum value appeared at different positions for different cutting conditions but had the same magnitude. And they fell to an identical level within $0.5 \mathrm{~mm}$ distance from the cutting edge. This trend was consistent with the results of Inconel 718.

\section{Conclusions and outlook}

The aim of this work was to further develop the CEL-based cutting fluid simulation. With the new models, convective cooling at the tool rake face was investigated. The experimental analysis and simulations led to the following conclusions:

- The flood cooling creates a stationary zone of material flow in the cutting area. This stagnation zone occurred not only between the chip and the tool but distributed along the tool rake face by about $3 \mathrm{~mm}$ from the tool tip. It hindered the cutting fluid from acting directly on the tool-chip interface, thus reduced cooling effect.

- Simulation of heat flux and heat transfer coefficient on the tool rake face revealed that the distribution of convective heat transfer coefficient was 
similar for different cutting parameters, and its maximum and steady values were not affected by the cutting parameters.

- The CEL method overestimates the convective cooling because the flow velocity in the boundary layer was not modeled with sufficient accuracy. Therefore, the convective heat transfer coefficient must be determined by further research and applied in the CEL simulation.

In future studies, more cutting conditions will be investigated to confirm the regularity of the convective heat transfer coefficient distribution found in this work. Furthermore, the two-dimensional approach is not applicable to high-pressure cooling, because the side flow is not negligible under highpressure conditions. Therefore, in future work, the CEL model should be extended to 3D so that it can be widely used for different cooling conditions.

Acknowledgments. The authors would like to thank the German Research Foundation (DFG) for the funding of the depicted research within the project "Development of a 3D multiphysics model for the analysis of the thermomechanical cooling lubricant effect in machining" (KL 500/203-1). Furthermore, the authors appreciate Sandvik Tooling Deutschland GmbH for providing cutting tools.

\section{Declarations}

- Funding: The research leading to these results received funding from German Research Foundation (DFG) under Grant Agreement No. [KL 500/203-1].

- Conflict of interest: The authors declare no competing interests.

- Availability of data and materials: Not applicable

- Code availability: Not applicable

\section{References}

[1] Klocke, F., Schulz, A., Gerschwiler, K. (eds.): Saubere Fertigungstechnologien - Ein Wettbewerbsvorteil Von Morgen? Aachener Werkzeugmaschinen-Kolloquium: Aachener Perspektiven, Sonderausg edn. VDI-Verl., Düsseldorf (1996)

[2] Sørby, K., Tønnessen, K.: High-pressure cooling of face-grooving operations in ti6al4v. Proceedings of the Institution of Mechanical Engineers, Part B: Journal of Engineering Manufacture 220(10), 1621-1627 (2006). https://doi.org/10.1243/09544054JEM474

[3] Diniz, A.E., Micaroni, R.: Influence of the direction and flow rate of the cutting fluid on tool life in turning process of aisi 1045 steel. International Journal of Machine Tools and Manufacture 47(2), 247-254 (2007). https: //doi.org/10.1016/j.ijmachtools.2006.04.003 
[4] Li, X.: Study of the jet-flow rate of cooling in machining part 2. simulation study. Journal of Materials Processing Technology 62(1-3), 157-165 (1996). https://doi.org/10.1016/0924-0136(95)02198-1

[5] Courbon, C., Sajn, V., Kramar, D., Rech, J., Kosel, F., Kopac, J.: Investigation of machining performance in high pressure jet assisted turning of inconel 718: A numerical model. Journal of Materials Processing Technology 211(11), 1834-1851 (2011). https://doi.org/10.1016/j.jmatprotec. 2011.06.006

[6] Fallenstein, F., Aurich, J.C.: Cfd based investigation on internal cooling of twist drills. Procedia CIRP 14, 293-298 (2014). https://doi.org/10.1016/ j.procir.2014.03.112

[7] Beer, N., Özkaya, E., Biermann, D.: Drilling of inconel 718 with geometrymodified twist drills. Procedia CIRP 24, 49-55 (2014). https://doi.org/ 10.1016/j.procir.2014.07.124

[8] Fang, Z., Obikawa, T.: Turning of inconel 718 using inserts with cooling channels under high pressure jet coolant assistance. Journal of Materials Processing Technology 247, 19-28 (2017). https://doi.org/10.1016/j. jmatprotec.2017.03.032

[9] Klocke, F., Döbbeler, B., Peng, B., Lakner, T.: Fe-simulation of the cutting process under consideration of cutting fluid. Procedia CIRP 58, 341-346 (2017). https://doi.org/10.1016/j.procir.2017.03.235

[10] Helmig, T., Peng, B., Ehrenpreis, C., Augspurger, T., Frekers, Y., Kneer, R., Bergs, T.: A coupling approach combining computational fluid dynamics and finite element method to predict cutting fluid effects on the tool temperature in cutting processes. Journal of Manufacturing Science and Engineering 141(10) (2019). https://doi.org/10.1115/1.4044102

[11] Oezkaya, E., Iovkov, I., Biermann, D.: Fluid structure interaction (fsi) modelling of deep hole twist drilling with internal cutting fluid supply. CIRP Annals 68(1), 81-84 (2019). https://doi.org/10.1016/j.cirp.2019. 03.003

[12] Klocke, F.: Manufacturing Processes 1: Cutting. RWTHedition. Springer-Verlag Berlin Heidelberg, Berlin, Heidelberg (2011). https://doi.org/10.1007/978-3-642-11979-8. http://site.ebrary.com/lib/alltitles/docDetail.action?doclD=10472459

[13] Benson, D.J.: Computational methods in lagrangian and eulerian hydrocodes. Computer Methods in Applied Mechanics and Engineering 99(2-3), 235-394 (1992). https://doi.org/10.1016/0045-7825(92)90042-I 
[14] Hardt, M., Bergs, T.: Considering multiple process observables to determine material model parameters for fe-cutting simulations. The International Journal of Advanced Manufacturing Technology 113(11-12), 3419-3431 (2021). https://doi.org/10.1007/s00170-021-06845-6

[15] Johnson, G.R., Cook, W.H.: A constitutive model and data for metals subjected to large strains, high strain rates and high temperatures. Proceedings of the 7th International Symposium of Ballistics 1983

[16] Jaspers, S.P.F.C., Dautzenberg, J.H.: Material behaviour in conditions similar to metal cutting: flow stress in the primary shear zone. Journal of Materials Processing Technology 122(2-3), 322-330 (2002). https://doi. org/10.1016/S0924-0136(01)01228-6

[17] Ozel, T., Sima, M., Özel, T.: Modified material constitutive models for serrated chip formation simulations and experimental validation in machining of titanium alloy ti-6al-4v. International Journal of Machine Tools and Manufacture 50(11), 943-960 (2010). https://doi.org/10.1016/ j.ijmachtools.2010.08.004

[18] Johnson, G.R., Cook, W.H.: Fracture characteristics of three metals subjected to various strains, strain rates, temperatures and pressures. Engineering Fracture Mechanics 21(1), 31-48 (1985). https://doi.org/10. 1016/0013-7944(85)90052-9

[19] Abouridouane, M., Klocke, F., Lung, D., Veselovac, D.: The mechanics of cutting: In-situ measurement and modelling. Procedia CIRP 31, 246-251 (2015). https://doi.org/10.1016/j.procir.2015.03.048

[20] Puls, H., Klocke, F., Lung, D.: Experimental investigation on friction under metal cutting conditions. Wear 310(1-2), 63-71 (2014). https:// doi.org/10.1016/j.wear.2013.12.020

[21] Seimann, M., Peng, B., Fischersworring-Bunk, A., Rauch, S., Klocke, F., Döbbeler, B.: Model-based analysis in finish broaching of inconel 718. The International Journal of Advanced Manufacturing Technology 97(9-12), 3751-3760 (2018). https://doi.org/10.1007/s00170-018-2221-5

[22] Erice, B., Gálvez, F.: A coupled elastoplastic-damage constitutive model with lode angle dependent failure criterion. International Journal of Solids and Structures 51(1), 93-110 (2014). https://doi.org/10.1016/j.ijsolstr. 2013.09.015

[23] Bahrami, M., Yovanovich, M.M., Culham, J.R.: Thermal joint resistances of nonconforming rough surfaces with gas-filled gaps. Journal of Thermophysics and Heat Transfer 18(3), 326-332 (2004). https://doi.org/10. $2514 / 1.5482$ 
[24] Norouzifard, V., Hamedi, M.: Experimental determination of the toolchip thermal contact conductance in machining process. International Journal of Machine Tools and Manufacture 84, 45-57 (2014). https: //doi.org/10.1016/j.ijmachtools.2014.04.003

[25] Denkena, B., Tönshoff, H.K.: Spanen. Springer Berlin Heidelberg, Berlin, Heidelberg (2011). https://doi.org/10.1007/978-3-642-19772-7

[26] Müller, B., Renz, U.: Development of a fast fiber-optic two-color pyrometer for the temperature measurement of surfaces with varying emissivities. Review of Scientific Instruments 72(8), 3366-3374 (2001). https://doi. org/10.1063/1.1384448

[27] Bergs, T., Hardt, M., Schraknepper, D.: Determination of johnson-cook material model parameters for aisi 1045 from orthogonal cutting tests using the downhill-simplex algorithm. Procedia Manufacturing 48, 541552 (2020). https://doi.org/10.1016/j.promfg.2020.05.081 